\title{
Determination of Triacetone Triperoxide and Hexamethylene Triperoxide Diamine in Various Matrices Using Infrared Spectroscopy
}

\begin{tabular}{|c|c|}
\hline Journal: & Applied Spectroscopy \\
\hline Manuscript ID & ASP-18-0112.R1 \\
\hline Manuscript Type: & Submitted Manuscript \\
\hline $\begin{array}{r}\text { Date Submitted by the } \\
\text { Author: }\end{array}$ & 14-Sep-2018 \\
\hline Complete List of Authors: & $\begin{array}{l}\text { Vodochodský, Ondřej; University of Pardubice, Faculty of Chemical } \\
\text { Technology, Institute of Energetic Materials } \\
\text { Jalový, Zdeněk; University of Pardubice, Faculty of Chemical Technology, } \\
\text { Institute of Energetic Materials } \\
\text { Matyáš, Robert; University of Pardubice, Faculty of Chemical Technology, } \\
\text { Institute of Energetic Materials } \\
\text { Novotná, Miroslava; University of Chemistry and Technology Prague, } \\
\text { Central Laboratories, Laboratory of Infra-Red (IR) and Raman } \\
\text { Spectroscopy }\end{array}$ \\
\hline Manuscript Keywords: & $\begin{array}{l}\text { TATP, HMTD, homemade plastic explosives, FT-IR analysis of homemade } \\
\text { explosives }\end{array}$ \\
\hline Abstract: & $\begin{array}{l}\text { The method for quantitative analysis of triacetone triperoxide (TATP) and } \\
\text { hexamethylene triperoxide diamine (HMTD) in different matrices is } \\
\text { presented. The method is suitable for polymer, plastic or cellulose } \\
\text { matrices. It is based on dissolving, or extraction of, peroxide in the } \\
\text { solvent and measurement in cuvettes using the FT-IR technique. These } \\
\text { methods may be useful in analytical methods of explosive detection and } \\
\text { determination. }\end{array}$ \\
\hline \multicolumn{2}{|c|}{$\begin{array}{l}\text { Note: The following files were submitted by the author for peer review, but cannot be converted to PDF. } \\
\text { You must view these files (e.g. movies) online. }\end{array}$} \\
\hline \multicolumn{2}{|c|}{ ASP-18-0112.R1_Jalovy_Figures.zip } \\
\hline
\end{tabular}

\section{SCHOLARONE ${ }^{\text {tw }}$ Manuscripts}




\title{
Determination of Triacetone Triperoxide and Hexamethylene Triperoxide Diamine in Various Matrices Using Infrared Spectroscopy
}

\author{
Ondřej Vodochodský ${ }^{1}$, Zdeněk Jalový ${ }^{1}$, Robert Matyáš ${ }^{1}$, Miroslava Novotná ${ }^{2}$ \\ ${ }^{1}$ University of Pardubice, Faculty of Chemical Technology, Institute of Energetic Materials, \\ Studentská 95, Pardubice, CZ-532 10, Czech Republic \\ ${ }^{2}$ University of Chemistry and Technology Prague, Central Laboratories, Laboratory of Infra-Red \\ and Raman Spectroscopy, Technická 5, Prague 6, CZ-166 28, Czech Republic
}

\section{Corresponding author}

Zdeněk Jalový, University of Pardubice, Materials, Faculty of Chemical Technology, Institute of Energetic, Studentská 95, Pardubice, 53210, Czech Republic

Email: zdenek.jalovy@upce.cz

\begin{abstract}
The method for quantitative analysis of triacetone triperoxide (TATP) and hexamethylene triperoxide diamine (HMTD) in different matrices is presented. The method is suitable for polymer, plastic, or cellulose matrices. It is based on dissolving, or extraction of, peroxide in the solvent and measurement in cuvettes using the FT-IR technique. These methods may be useful in analytical methods of explosive detection and determination.

Keywords: Triacetone triperoxide, TATP, hexamethylene triperoxide diamine, HMTD, homemade plastic explosives, Fourier transform infrared, FT-IR, analysis of homemade explosives

\section{Introduction}

Triacetone triperoxide (3,3,6,6,9,9-hexamethyl-1,2,4,5,7,8-hexaoxonane, TATP) and hexamethylene triperoxide diamine (3,4,8,9,12,13-hexaoxa-1,6-diazabicyclo[4,4,4]tetradecane, HMTD, Fig. 1) are primary explosives. ${ }^{1-3}$ Due to their low long term physical (TATP) and chemical (HMTD) stability as well as the low thermal stability of both peroxides ${ }^{4-7}$ they have not been found suitable for use in industrial primary explosive production. ${ }^{8-9}$
\end{abstract}


$<$ Insert Figure 1>

However, the simplicity of their preparation, the availability of the starting materials and a well understood/known fabrication method (which is advertised widely via the internet) make TATP and HMTD ideal for those wishing to misuse such compounds for criminal or terrorist purposes ${ }^{10}$ For example, HMTD was planned to be used as the primary explosive for intended bomb attack on Los Angeles International Airport during the 2000 millennium celebrations. ${ }^{11}$ Triacetone triperoxide is an improvised explosive that is considered as the one used for the London bombings on June $7^{\text {th }} 2005^{12}$ and, together with another homemade explosive, pentaerythritol tetranitrate (PETN), for a failed bombing attempt on Northwest Airlines Flight 253 from Amsterdam to Detroit on Christmas day, 25 December 2009. ${ }^{13}$ TATP was also used in the Paris attacks in November $2015^{14}$ and in the Brussels bombings in March 2016. ${ }^{15-16}$ All of the above examples demonstrate that TATP and HMTD are still frequently being used as homemade explosives. They are not used only as individual explosives, but also in mixtures with other substances, which improve the various parameters of the final explosive mixture. For example, TATP and HMTD are sometimes used for the preparation of attractive homemade plastic explosives, in combination with some polymer binders, mineral oils etc. ${ }^{17-18}$ Numerous other homemade explosives based on TATP and HMTD can be found on extremist websites.

From the above it is obvious that these organic peroxides are often the subject of analysis in forensic laboratories. Such analyses generally focus on the identification of the explosive in any samples obtained, and the determination of the correct concentration of the explosive in different matrices, in order to provide an abundant level of proof for the courts. Items containing peroxides for analysis may be plastic explosives, but also any materials contaminated by peroxides from their preparation and storage, such as filter papers.

In addition, some training materials for sniffer dogs are based on explosives introduced into a cellulose matrix. The amount of peroxide in the matrices must be quantified to check the quality and safety of the product. The content of the peroxide in the material has to be between the minimal amount to guarantee both proper functioning and sufficient peroxide vapor pressure and the maximum admissible amount to ensure safety in handling the training material. ${ }^{19}$

In recent years, various analytical methods have been described for qualitative and quantitative determination of organic peroxide explosives. ${ }^{20-21}$ Fourier transform infrared (FTIR) spectroscopy has been used for a long time for the identification of both the peroxides in the 
current study. ${ }^{22-25}$ The advantages of FT-IR analysis are the availability of spectrometers in laboratories plus the possibility of having portable FT-IR spectrometers at the scene of the crime for immediate identification, easy sample manipulation, low risk of contamination of inner parts of the device by inappropriate materials (e.g., contamination of LC columns by polymers or plastics) and usually rapid results.

The current work has focused on direct qualitative and quantitative determination of peroxides via FT-IR. We present here the FT-IR identification and determination of the amount of TATP and HMTD in polymers, oils, and cellulose matrices, using cuvettes and multireflection attenuated total reflection (ATR) crystals.

\section{Experimental}

\section{Caution}

TATP and HMTD are highly sensitive primary explosives. Synthesis and handling of these explosives are hazardous and all the safety precautions for handling primary explosives need to be strictly followed even when working with small quantities.

\section{Synthesis}

Triacetone triperoxide was prepared in gram scale from acetone and hydrogen peroxide (30\%) catalyzed by hydrochloric acid. The molar ratio of catalyst to acetone was 0.25 , and the molar ratio of acetone to hydrogen peroxide was $1.25 .^{26}$

Hexamethylene triperoxide diamine was prepared according to the Girsewald procedure from hexamethylene tetramine, hydrogen peroxide (30\%) and citric acid. ${ }^{27,28}$ The molar ratio of citric acid to hexamethylene tetramine was 1.0 , and the molar ratio of hexamethylene tetramine to hydrogen peroxide was $0.25 .^{29}$

\section{Peroxide Formulation Preparation}

Plastic explosives with TATP and HMTD were prepared using Vaseline Mogul A00 or mineral oil OEMIN-Kolben 1.0 as a plasticizer by carefully incorporating the organic peroxide into the binder. Polymer-bonded explosives (PBXs) with TATP or HMTD were prepared using polystyrene as a binder by dissolving the polystyrene in toluene, addition of peroxide and removing of the solvent as described by Vodochodský and Matyás. ${ }^{17}$ The amount of organic 
peroxide in the plastic explosive was in the range of $60-70 \%$. The physical appearance of some peroxide formulations with a plastic binder is illustrated in Fig. 2.

Cellulose kits for training of dogs to detect explosives were prepared by incorporating HMTD or TATP into the cellulose matrix. ${ }^{19}$

\section{Apparatus and Solvents}

The infrared spectra were collected using a Nicolet iS50 FT-IR spectrometer (Thermo Scientific, USA) with an ATR single reflection diamond accessory GladiATR (Pike) and a zinc selenide ten reflection ATR accessory GladiATR (Pike). Measurement parameters were the spectral region $4000-400 \mathrm{~cm}^{-1}$, resolution $4 \mathrm{~cm}^{-1}$ and the number of scans was 64 . For transmission, barium fluoride and sodium chloride cuvette windows with $0.5 \mathrm{~mm}$ spacers were used. Filters used for dosing of the sample solutions to the cuvette were Profill PTFE/ $0.2 \mu \mathrm{m}$. OMNIC 9.3 software was used for collection as well as work with the collected spectra. TQ analyst 9.4 software was used for calibration and quantitative analysis evaluation.

Dimethylsulfoxide (99.8+ \%, Acros) and chloroform (p.a., Penta) were used as solvents for dissolving peroxides. Chloroform of p.a. purity stabilized by amylene, 55 parts per million (ppm), was distilled before use to obtain a suitable purity for spectroscopic analysis.

High-performance liquid chromatography (HPLC) analysis was performed using an Agilent 1200 Series (Thermo) with reverse-phase column Separon SGX C-18, particle size $5 \mu \mathrm{m}$. A 60:40 acetonitrile-water mixture was used as the mobile phase. Evaluation at $210 \mathrm{~nm}$.

\section{Processes for Analyte Preparation}

Plastic explosive samples (peroxides in mineral oil) were dissolved in dimethylsulfoxide using the following procedure: nominally $50 \mathrm{mg}( \pm 0.10 \mathrm{mg}$, with an accuracy of $0.1 \mathrm{mg})$ of plastic explosive with TATP or HMTD and mineral oil were placed in a $10 \mathrm{~mL}$ volumetric flask, $10 \mathrm{~mL}$ of DMSO (weighed with an accuracy of $0.1 \mathrm{mg}$ ) were added and the flask closed with a stopper. The mixture was placed in an ultrasonic bath for 20-30 minutes. After dissolving of all the plastic explosive in the solvent, the sample was placed in the barium fluoride cuvette or on an ATR crystal.

Peroxides in the polystyrene matrix (PBX) or in Vaseline (plastic explosives) were determined as follows: nominally $50 \mathrm{mg}( \pm 0.10 \mathrm{mg}$, with an accuracy of $0.1 \mathrm{mg})$ of the sample 
with organic peroxide and Vaseline or polystyrene were placed in a $10 \mathrm{~mL}$ volumetric flask, $10 \mathrm{~mL}$ of chloroform (weighed with an accuracy of $0.1 \mathrm{mg}$ ) were added and the flask closed with a stopper. The mixture was placed in an ultrasonic bath for 15-30 minutes. After all the plastic was dissolved in the solvent, the sample was placed in the sodium chloride cuvette.

The determination of the peroxide amount in the cellulose matrix was as follows: TATP or HMTD were extracted from cellulose (filter paper, training kits for dogs) with dimethylsulfoxide using ultrasound. The typical procedure for peroxides in cellulose-based training kits (expected content of peroxide 0.1-10\%) was $1 \mathrm{~g}( \pm 0.25 \mathrm{~g})$ of cellulose with peroxide was weighed with an accuracy of $0.1 \mathrm{mg}$, placed in an Erlenmeyer flask, $15 \mathrm{~mL}$ of dimethylsulfoxide (p.a.) were added (weighed with an accuracy of $0.1 \mathrm{mg}$ ) and the flask closed with a stopper. The mixture was put into an ultrasonic bath for 20-30 minutes and then dosed by injection from a syringe through a filter to a cuvette with a barium fluoride window or to a ten reflection ATR accessory.

\section{Calibration Solutions and Cuvette Thickness}

At least five calibration solutions for each calibration were prepared by dissolving a given quantity (to cover the range) of peroxide in $10 \mathrm{~mL}$ of solvent in a $10 \mathrm{~mL}$ volumetric flask. The solvent was weighed with an accuracy of $0.1 \mathrm{mg}$. The flask was placed in an ultrasonic bath for 10-15 minutes. The range of calibration for each peroxide and solvent is shown in Table I.

Table I. Overview of the range for calibration settings.

\begin{tabular}{lll}
\hline Peroxide/solvent & Range $(\mathrm{g} / 10 \mathrm{~mL})$ & Range $(\mathrm{wt} \%)$ \\
\hline TATP/dimethylsulfoxide & $0.005-0.150$ & $0.04-1.5$ \\
TATP/chloroform & $0.005-0.080$ & $0.03-0.5$ \\
HMTD/dimethylsulfoxide & $0.005-0.100$ & $0.04-1.0$ \\
HMTD/chloroform & $0.005-0.070$ & $0.03-0.5$ \\
\hline
\end{tabular}

Calibration for TATP and HMTD in dimethylsulfoxide was suitable for a ten reflection ATR accessory and for measuring in a barium fluoride cuvette. Calibration for TATP and HMTD in chloroform was suitable for measuring in sodium chloride cuvette. The width of the cuvettes was $0.5 \mathrm{~mm}$ in both cases. 


\section{Results and Discussion}

\section{Qualitative Analysis}

The presence of both TATP and HMTD in plastic explosives with Vaseline or mineral oil may be detected directly by FT-IR using the single reflection ATR technique. The FT-IR spectra of plastic explosives with organic peroxide content $60-70 \%$ mainly correlate with organic peroxide spectra (Fig. 3). The presence of organic peroxides in filter paper used for filtration of the product (after preparation of peroxide) is visible by direct measurement and can be identified by comparison of the spectra with standard. If the content of organic peroxide in cellulose matrices is lower (e.g., in training kits or in filter paper after some of the peroxide is washed away or evaporated), the presence of peroxides is evident after subtraction of cellulose by software subtraction, or collecting the sample spectra after cellulose has been used as a background as shown in Fig 4. TATP (or HMTD) on a filter paper can be identified even if the amount of peroxide is as low as $1.5 \%$.

\section{Quantitative Analysis}

For determining the content of organic peroxides in matrices, the peroxide must be used in solutions, so that the quantitative technique in a cuvette or with an ATR crystal may be applied. Cuvettes with a pathlength of $0.5 \mathrm{~mm}$ were used as in the procedure described in the experimental section. Regarding the ATR technique, to get a sufficient level of absorbance, multireflection ATR crystals should be used, with ten reflections in the crystal being found to be optimal for measuring samples in this case.

Dimethylsulfoxide and chloroform were used as the solvents for dissolving plastic matrices with TATP or HMTD and extraction of peroxides from cellulose. These solvents meet the criteria of sufficient ability to dissolve TATP and HMTD, compatibility with cuvette materials and the FT-IR spectrum of a real sample has a sufficient number of peroxide bands not overlapped with the solvent or other components of the matrix. As for solubility, many solvents that were considered (e.g., acetonitrile or dimethylformamide) cannot dissolve a sufficient amount of HMTD, which is poorly soluble in most solvents. ${ }^{5}$

Sodium chloride cuvettes are suitable for chloroform solutions and barium fluoride cuvettes can be used for samples dissolved in dimethylsulfoxide. For measurement using internal 
reflection elements (IRE), dimethylsulfoxide is the preferred solvent because chloroform may partially evaporate.

Prepared samples are not intended for long-term storage. We recommend analyzing solutions, especially for HMTD, without any unnecessary delay and preferably within a few days after preparation. HMTD is not generally stable in the solvents and its concentration diminishes in time. The decrease in concentration of HMTD in a dimethylsulfoxide solution stored at a temperature of $21^{\circ} \mathrm{C}$ was approx. $5 \mathrm{wt} \%$ after a week and $20 \mathrm{wt} \%$ after six weeks.

Different matrices require different techniques for analyte preparation. Because cellulose is not soluble in dimethylsulfoxide or chloroform, TATP or HMTD should be extracted from cellulose matrices before proceeding to analysis. An ultrasonic bath was used for extraction and to transfer the extract to the cuvette. A syringe with a filter was used to hold solid particles which could affect the measurement.

Plastic explosives and PBXs with peroxides are soluble in chloroform or dimethylsulfoxide depending on the composition and there is no possibility of selective extraction of peroxides. Plastic explosives with mineral oil as a binder are dissolved in dimethylsulfoxide. Vaseline and polystyrene are not soluble in dimethylsulfoxide at the level required for this analysis and so explosives with these binders should be dissolved in chloroform.

It is necessary to prepare solutions in suitable concentrations, so that the concentration of organic peroxide is below the solubility limit and a complete dissolution of all the peroxide can be guaranteed.

To determine the peroxide content there are several bands suitable for all the matrices described. Combinations of peroxide with solvents are summarized in Table II, where the most suitable bands are marked in bold. The detailed assignments of some bands of organic peroxides are published in the literature, for example. ${ }^{30-32}$

Table II. Frequencies of possible bands for quantitative analysis.

\begin{tabular}{ll}
\hline Peroxide/solvent & Band frequencies suitable for evaluation \\
\hline TATP/CHCl & \\
TATP/DMSO & $\mathbf{1 3 6 7}, 1274,945, \mathbf{8 8 5} \mathrm{cm}^{-1}$ \\
$\mathrm{HMTD} / \mathrm{CHCl}_{3}$ & $1234,1201,1185, \mathbf{8 4 4}, 787 \mathrm{~cm}^{-1}$ \\
$\mathrm{HMTD} / \mathrm{DMSO}$ & $1391, \mathbf{1 3 5 9}, \mathbf{1 3 3 4}, 1053,1036, \mathbf{9 8 0}, 957,878 \mathrm{~cm}^{-1}$ \\
\hline
\end{tabular}




\section{$<\mathrm{AQ}>$ Please provide an explanation for the frequencies in bold in Table II. $</ \mathrm{AQ}>$}

For peaks mentioned in Table II, the presence of binder (mineral oil, Vaseline, or polystyrene) does not affect the overall absorption of the sample, as illustrated for HMTD in chloroform. This was verified on samples with $100 \%$ concentration of the binder (no peroxide). This is shown in Fig. 5, where spectra of solvents with binders are compared to spectra of pure solvent and spectra of solvent with peroxide content.

The dependence of absorbance on concentration of the peroxide in the measured samples for the various bands mentioned in Table II for dimethylsulfoxide is demonstrated in Fig. 6.

The software evaluation of the readings was performed with the TQ Analyst software using the linear dependence of absorbance on concentration in accordance with Beer-Lambert law. In the ideal case, the evaluation was done for bands and frequencies with zero baseline absorbance. Nevertheless, the evaluation is possible even for bands that do not have a flat baseline (shown in Fig. 7). Evaluation is possible from both the height of the peaks as well as from the peak area within the selected wavenumber range.

The quantitative analysis methods mentioned above were verified. Samples with known concentrations of organic peroxides were measured and the results of the analysis were compared with known concentrations.

A cellulose matrix with TATP or HMTD was prepared and the concentration of organic peroxides was determined using HPLC. For samples of plastic explosives, no other analytical method is known or available to us, which is also the reason for developing the method described in this paper. The concentration of organic peroxides in the plastic explosives was determined from the amount of TATP or HMTD that was used for preparation of such plastic explosives. Cellulose, containing organic peroxides, was analyzed using the dimethylsulfoxide method mentioned above. Calibration of TATP in dimethylsulfoxide was evaluated from the peak area for region 1205-1197 $\mathrm{cm}^{-1}$, with two points fixed as baseline at 1209.15 and $1193.72 \mathrm{~cm}^{-1}$. That gave us the calibration Eq. $1, A=2.87 x+0.0102, \mathrm{R}=0.9999$, where $A$ is absorbance, $x$ is concentration in weight percent and $\mathrm{R}$ is reliability factor. The concentration of TATP in the sample measured calculated using this equation was $2.5 \%$, which corresponds to the HPLC result (2.5\%). The calibration Eq. 2 for HMTD in dimethylsulfoxide was $A=16.9 x+0.0807, \mathrm{R}=0.9998$ for the peak area $1230-1222 \mathrm{~cm}^{-1}$ with baseline points at 1240.00 and $1209.15 \mathrm{~cm}^{-1}$. The result 
for the sample measured was $2.1 \%$ of HMTD in cellulose and was again the same as for the HPLC analysis. The areas used for evaluation are also shown in Fig. 6 for both peroxides. Plastic explosives were prepared using organic peroxides and Vaseline. Chloroform was used as the solvent for analysis of these samples. Calibration of TATP in chloroform was performed for peak area $889-881 \mathrm{~cm}^{-1}$ with one baseline point fixed at $894.81 \mathrm{~cm}^{-1}$. The calibration equation obtained was $A=4.96 x+0.0120, R=0.9999$ (3). The concentration of TATP in the sample measured was calculated as $61.7 \%$, which is very near to the amount used for the sample preparation (61.5\%). The calibration equation for HMTD in chloroform was $A=17.3 x-0.144$, $\mathrm{R}=0.9998$ (4), for an area $987-975 \mathrm{~cm}^{-1}$ and one baseline point at $968.09 \mathrm{~cm}^{-1}$. The analysis of the sample measured again corresponded well to the peroxide content. A plastic explosive with approx. $60.3 \%$ of HMTD was prepared and FT-IR analysis gave a result of $60.2 \%$. Peaks that were used for quantitative analysis are shown in Fig. 7. The results are summarized in Table III.

Table III. Results of quantitative analysis and validation.

\begin{tabular}{llllll}
\hline Sample & $\begin{array}{l}\text { Calibration } \\
\text { equation }\end{array}$ & $\begin{array}{l}\text { Range for } \\
\text { calibration } \\
\left(\mathrm{cm}^{-1}\right)\end{array}$ & $\begin{array}{l}\text { Base line } \\
\text { points }\left(\mathrm{cm}^{-}\right.\end{array}$ & $\begin{array}{l}\text { Concentration } \\
\text { using FT- }\end{array}$ & $\begin{array}{l}\text { Validation } \\
\text { IR }(\%)\end{array}$ \\
\hline TATP in & $A=2.87 x+0.0102$ & $1205-1197$ & 1209.15 & 2.5 & $2.5^{\mathrm{a}}$ \\
cellulose & $\mathrm{R}=0.9999(1)$ & & 1193.72 & & \\
HMTD in & $A=16.9 x+0.0807$ & $1230-1222$ & 1240.00 & 2.1 & $2.1^{\mathrm{a}}$ \\
cellulose & $\mathrm{R}=0.9998(2)$ & & 1209.15 & & $61.5^{\mathrm{b}}$ \\
TATP & $A=4.96 x+0.0120$ & $889-881$ & 894.81 & 61.7 & $60.3^{\mathrm{b}}$ \\
plastic & $\mathrm{R}=0.9999(3)$ & & & & \\
HMTD & $A=17.3 x-0.144$ & & & & \\
plastic & $\mathrm{R}=0.9998(4)$ & $987-975$ & 968.09 & & \\
\hline
\end{tabular}

a According to HPLC; ${ }^{b}$ according to amount used for preparation

\section{Conclusion}

This study provides a method for analyzing the organic peroxides triacetone triperoxide and hexamethylene triperoxide diamine using FT-IR. It is possible to detect and determine organic peroxides in polymer, plastic, or cellulose materials. Detection may be provided using a simple 
ATR technique, which can be useful for mobile on-site spectrometers. The preparation of the samples for quantitative analysis can be accomplished by dissolving or extraction. In the case of plastic binders, all formulations were dissolved in dimethylsulfoxide or chloroform. In the case of cellulose, peroxides were extracted from the matrix. The quantitative measurement was carried out by using cuvettes with barium fluoride or sodium chloride windows. Non-volatile samples with DMSO can be analyzed using a ten reflection ATR accessory.

\section{Acknowledgments}

This research was supported by the Ministry of Interior of the Czech Republic (Project No. VG20102014032). We would also like to thank Monika Šubrtová for graphical processing of FTIR spectra.

\section{References}

1. R. Matyáš, J. Pachman. Primary Explosives. Heidelberg: Springer, 2013. Pp 25-32.

2. K. Yeager. "Dangerous Innovations”. In: R. Woodfin, editor. Trace Chemical Sensing of Explosives. Hoboken, NJ: John Wiley \& Sons Inc., 2007. Pp 55-63.

3. R. Matyáš, J. Šelešovský, T. Musil. "Sensitivity to Friction for Primary Explosives". J. Hazard. Mater. 2012. 213-214: 236-241.

4. R. Matyáš, J. Pachmáň. “Thermal Stability of Triacetone Triperoxide”. Sci. Technol. Energ. Mater. 2007. 68(4): 111-116.

5. C.A. Taylor, W.H. Rinkenbach. "HMTD, a New Detonating Explosive”. Army Ordnance. 1924. 5: 463-466.

6. D. Sülze, P. Klaeboe. “The Infrared, Raman and NMR Spectra of Hexamethylene Triperoxide Diamine". Acta Chem. Scand. 1988. A42: 165-170.

7. H. Ficheroulle, A. Kovache. "Contribution à l'étude des Explosifs d'Amorçage”. Meml. Poudres. 1949. 31: 7-27.

8. B.T. Fedoroff, H.A. Aaronson, E.F. Reese, et al. Encyclopedia of Explosives and Related Items. New Jersey: Picatinny Arsenal, 1960. Vol. 1. Pp. A42-A44.

9. B.T. Fedoroff, O.E. Sheffield. Encyclopedia of Explosives and Related Items. New Jersey: Picatinny Arsenal, 1975. Vol. 7. Pp. H83-H84. 
10. J.C. Oxley. "What's Special about Liquid Explosives?” In: H. Schubert, A, Kuznetsov, editor. Detection of Liquid Explosives and Flammable Agents in Connection with Terrorism. NATO Science for Peace and Security Series B: Physics and Biophysics. Dordrecht, Springer, 2007. Pp 27-38.

11. K. Yeager. "Improvised Explosives Characteristics, Detection and Analysis". In: A. Beveridge, editor. Forensic Investigation of Explosions. Boca Raton, FL: CRC Press, 2012. Pp. 496.

12. IED Attack: Improvised Explosive Devices. http://www.dhs.gov/xlibrary/assets/prep_ied_fact_sheet.pdf [accessed Feb 06 2017]

13. Umar Farouk Abdulmutallab indictment, Case 2:10-cr-20005-NGE-DAS, Document 7. http://www.cbsnews.com/htdocs/pdf/Abdulmutallab_Indictment.pdf [accessed Feb 06 2017].

14. D. Mosher. "The Homemade Explosive Used in the Paris Attacks is a Chemical Nightmare". http://www.techinsider.io/paris-attack-tatp-chemical-bombs-2015-11 [accessed Oct 18 2017]. $<$ AQ >Please note: The title of Ref. 14 was changed to match that of the provided URL. $</ A Q>$

15. J. Callebaut. "Brussels Bombing 22 Mar 2016”. Presented at: 14th International Meeting of Pyrotechnicians INMEP, Boletice, Czech Republic; May 29-June 1, 2017.

16. B. Simoens, C. Huberty. “The Brussels Attacks-March 22, 2016”. Presented at: 12th International Symposium on Analysis and Detection of Explosives ISADE 2017, Keble College, Oxford, UK; September 17-21, 2017.

17. O. Vodochodský, R. Matyáš. “Improvised Explosives Based on TATP and HMTD”. Presented at: 13th International Meeting of Pyrotechnicians INMEP, Boletice, Czech Republic; May 5-June 3, 2016.

18. O. Vodochodský, R. Matyáš, Z. Jalový. "Homemade Plastic Explosives Based on TATP and HMTD-Properties and Analysis". Presented at: 12th International Symposium on Analysis and Detection of Explosives ISADE 2017, Keble College, Oxford, UK; September 17-21, 2017.

19. J. Pachmáň, R. Matyáš, O. Vodochodský, et al. Training Material Suitable Especially for Training of Dogs for Detection of Explosives and Process for Preparing Thereof. CZ Patent 305617. Filed 2014. Issued 2016. 
20. J. Yinon. Counterterrorist Detection Techniques of Explosives. Amsterdam: Elsevier, 2007. 21. J.S. Caygill, F. Davis, S.P.J. Higson. "Current Trends in Explosive Detection Techniques”. Talanta 2012. 88: 14-29.

22. S. Zitrin, S. Kraus, B. Glattstein. "Identification of Two Rare Explosives". Presented at: Int. Symp. Anal. Detect. Explos. March 29-31, Quantico, Virginia, 1983; published by US Department of Justice, Washington 1984. Pp. 137-141.

23. G.M. White. “An Explosive Drug Case”. J. Forensic Sci. 1992. 37(2): 652-656.

24. H.K. Evans, F.A.J. Tulleners, B.L. Sanchez, et al. "An Unusual Explosive, Triacetonetriperoxide (TATP)”. J. Forensic Sci. 1986. 31(3): 1119-1125.

25. R. Schulte-Ladbeck, A. Edelmann, G. Quintás, et al. "Determination of Peroxide-based Explosives Using Liquid Chromatography with On-Line Infrared Detection“. Anal. Chem. 2006. 78(23): 8150-8155.

26. R. Matyáš, J. Šelešovský. “Power of TATP Based Explosives”. J. Hazard. Mater. 2009. 165(1-3): 95-99.

27. C. Girsewald. Verfahren zur Darstellung von Hexamethylentriperoxyddiamin. DE Patent. 263459. Issued 1912.

28. C. Girsewald. "Beiträge zur Kenntnis des Wasserstoffperoxyds. Über die Einwirkung des Wasserstoffperoxyds auf Hexamethylentetramin”. Ber. Dtsch. Chem. Ges. 1912. 45(2): 2571-2576.

29. T. Urbański. Chemistry and Technology of Explosives. Warszawa: Polish Scientific Publisher, 1967. Vol. 3, pp. 225-226.

30. B. Brauer, F. Dubnikova, Y. Zeiri, et al. "Vibrational Spectroscopy of Triacetone Triperoxide (TATP): Anharmonic Fundamentals, Overtones and Combinations Bands”. Spectrochim. Acta, Part A. 2008. 71(4): 1438-1445.

31. G.A. Buttigieg, A.K. Knight, S. Denson, et al. "Characterization of the Explosive Triacetone Triperoxide and Detection by Ion Mobility Spectrometry". Forensic Sci. Int. 2003. 135(1): $53-59$.

32. J. Oxley, J. Smith, J. Brady, et al. "Raman and Infrared Fingerprint Spectroscopy of Peroxide-Based Explosives”. Appl. Spectrosc. 2008. 62(8): 906-915.

\section{Captions}


Fig. 1. Triacetone triperoxide and hexamethylene triperoxide diamine.

Fig. 2. TATP or HMTD in plastic explosive (left) and in PBX (right).

Fig. 3. FT-IR spectra of TATP (left) and HMTD (right) in Vaseline matrices compared to spectra of pure peroxide.

Fig. 4. Identification of TATP in cellulose matrices by software subtraction of cellulose.

Fig. 5. FT-IR spectra of polystyrene (PS) formulation with HMTD in chloroform measured in a sodium chloride cuvette.

Fig. 6. FT-IR spectrum of TATP (left), HMTD (right) and mineral oil in dimethylsulfoxide.

Fig. 7. Calibration set for flat or raised baseline for TATP (left) and HMTD (right). For HMTD, both peaks 980 and $957 \mathrm{~cm}^{-1}$ are suitable for quantitative analysis and give the same results. 